\title{
PROCESSO DE HARMONIZAÇÃO CONTABILÍSTICA INTERNACIONAL: TENDENCIAS ACTUAIS
}

\author{
Catarina Xavier Amaral
}

Neste artigo dedicamos a nossa atenção à problemática da harmonização contabilística internacional num contexto de crescente interpenetração e crescimento dos mercados económicos e financeiros, salientando-se as vantagens decorrentes da adopção de normas de contabilidade aceites internacionalmente e os obstáculos colocados pela diversidade de sistemas contabilísticos existentes.

A harmonização contabilistica internacional desenvolveu-se em duas vertentes, de acordo com a natureza do organismo que a leva a cabo: pública, isto é, sustentada no direito internacional público $e$ privada ou profissional, emitida por instituições de peritos em contabilidade, sem instrumentos jurídicos que garantam a sua aplicação.

Como exemplo da harmonização regional de carácter público mencionam-se as realizações da União Europeia, na sua tarefa de homogeneizar as legislações dos diferentes Estados Membros. Na harmonização de âmbito mundial e de carácter profissional destaca-se o trabalho desenvolvido pelo International Accounting Standards Committee (IASC), passando em análise as diferentes posturas face às suas normas, com especial referência para a adoptada pela União. Tudo isto com o objectivo específico de manifestar a importância que

\footnotetext{
* Instituto Universitário de Desenvolvimento e Promoção Social - Pólo de Viseu do Centro Regional das Beiras da Universidade Católica Portuguesa.
} 
este organismo adquiriu nos últimos anos, como normalizador mundial da informação financeira.

Palavras-chave: Normalização contabilística internacional, União Europeia, IASC, IOSCO.

\section{A NECESSIDADE DE HARMONIZAÇÃO}

Liberdade de circulação de pessoas e bens, tecnologias de informação (com especial destaque para o desenvolvimento do e-commerce), criação de grandes espaços a nível mundial ${ }^{1}$, crescente papel da Organização Mundial do Comércio, redes de transporte a nível internacional são, entre outros, alguns sinais que tornam mais evidente o fenómeno da globalização.

O fenómeno da globalização pode ser entendido como o processo pelo qual os mercados e a produção de diferentes continentes se tornam crescentemente interdependentes, em consequência do desenvolvimento dos fluxos do comércio internacional de bens e serviços, dos fluxos de capital e das transferências de tecnologia.

Neste contexto, o crescimento das empresas e a consequente necessidade de novos investidores veio realçar a importância da qualidade da informação financeira.

Como princípio orientador, podemos dizer que a informação financeira deverá ser credível, para que os utilizadores, a quem a mesma se destina (sejam eles investidores, financiadores, governo, trabalhadores, etc.), possam tirar conclusões correctas. No domínio da informação, os utentes apreciam uma leitura neutra, isto é, uma transcrição sem opinião, porque a elaboração de juízos de valor acabará sempre por aparecer e será uma consequência das suas reflexões.

Por conseguinte, a crescente interpenetração e crescimento dos mercados económicos e financeiros conduz à reconhecida necessidade de procura da minimização das inconsistências nos procedimentos contabilísticos, entre os diversos países. Torna-se urgente implementar um corpo de normas, aceite internacionalmente, por forma a assegurar que a informação que serve de base à tomada de decisões económicas por parte de todos os agentes seja transparente, compreensível, fiável, consistente e comparável à escala internacional. Isto porque as linhas orientadoras seleccionadas, para o tratamento da informação financeira em cada país, podem ter impactos profundos no relato financeiro de uma 
mesma entidade económica e conduzir a diferenças quanto aos resultados apurados nas demonstrações financeiras por parte da mesma ${ }^{2}$.

Actualmente, a informação financeira que é preparada para accionistas e outros interessados baseia-se num conjunto de princípios e procedimentos que variam de país para país. Em consequência, a ausência de comparabilidade entre os vários relatos financeiros conduz a situações cada vez mais indesejáveis, e isto porque:

- aumenta consideravelmente os custos de preparar a informação financeira - uma empresa multinacional terá de preparar tantas demonstrações financeiras quantos os países em que opera;

- as próprias empresas pretendem ter um sistema uniforme que lhes permita aferir do desempenho financeiro das suas unidades produtivas espalhadas por diferentes países;

- investidores e outros utentes da informação financeira, porque têm de conviver com esta magnitude de diferenças, principalmente quando pretendem analisar determinado sector de actividade à escala internacional, incorrem em despesas extra de análise com as consequências negativas a elas associadas. Por exemplo, podem não se aperceber de investimentos potencialmente lucrativos, uma vez que não compreendem ou não confiam na informação financeira que lhes está associada; ou, ao não se darem conta da natureza das diferenças contabilísticas, podem vir a tomar decisões financeiras pouco correctas.

Em virtude de todas estas dificuldades inerentes ao processo de análise económico-financeira, a concorrência entre os mercados de capitais mundiais é prejudicada e as empresas poderão ter de suportar elevados custos de capital, em resultado das dificuldades criadas em torno da compreensão da sua real situação económica e financeira. Mais ainda, a credibilidade da informação financeira é posta em causa se uma empresa relatar diferentes resultados em diferentes países, para o mesmo conjunto de transacções.

Por tudo isto, o número de interessados numa efectiva harmonização contabilística internacional é cada vez maior, sendo de destacar o International Accounting Standards Committee (IASC) ${ }^{3}$, as empresas multinacionais, as instituições financeiras de grande dimensão e outras organizações intergovernamentais como sejam a Organização para a Cooperação e Desenvolvimento Económico (OCDE), a Organização das Nações Unidas (ONU) ${ }^{4}$ e a União Europeia (UE) ${ }^{5}$.

Para BELKAOUI (1992: 480) são várias as vantagens da harmonização contabilística a nível internacional. Em primeiro lugar, 
muitos países ainda não têm um adequado conjunto de normas de contabilidade e auditoria. A adopção de normas aceites internacionalmente iria, não apenas eliminar os custos de levar a cabo um processo completo de normalização contabilística, mas também permitir que esses países fizessem parte da tendência contabilística dominante. De facto, a concepção, promulgação e imposição de normas de contabilidade envolve custos consideráveis e, mesmo ignorando as vantagens da uniformização, não seria de todo economicamente vantajoso que cada país encetasse o seu próprio processo. Em segundo lugar, a crescente internacionalização das economias mundiais e o aumento da interdependência entre as nações, ao nível do comércio internacional e dos fluxos de investimento, são argumentos de peso para a aceitação de normas internacionais de contabilidade e de auditoria. Esta internacionalização das normas irá, também, facilitar as transacções internacionais, a fixação de preços e as decisões de afectação dos recursos económicos, podendo tornar os mercados financeiros internacionais mais eficientes. Por último, a necessidade que as empresas têm de aumentar o seu capital, através de emissões públicas de acções e/ou obrigações, dada a insuficiência dos resultados retidos para financiar projectos e a facilidade de recurso a financiamentos estrangeiros, tem aumentado a necessidade de uma harmonização contabilística. Com efeito, os "fornecedores" de capital baseiam-se na informação financeira proporcionada pelas empresas para tomarem as melhores decisões de investimento e de financiamento e tendem a demonstrar uma preferência crescente por relatos financeiros comparáveis.

Não nos restam dúvidas de que a magnitude das transacções financeiras trans-fronteiriças, o comércio internacional de valores mobiliários e o investimento directo estrangeiro são enormes, quer nas grandes, quer nas pequenas economias. A necessidade de ter, por isso, um único conjunto de regras, pelas quais medir e reconhecer activos, passivos e resultados, tem carácter de urgência.

Os obstáculos, frequentemente levantados a esta harmonização, têm a sua origem nas diferenças existentes entre os países de todo o mundo, diferenças essas que, como salientam NOBES e ALEXANDER (1994), podem ser derivadas dos sistemas legais, dos destinatários da informação, do sistema fiscal, do poder, da dimensão e da competência dos organismos profissionais, do nível de teoria e pesquisa contabilística e da própria cultura e desenvolvimento histórico. 


\section{DIVERSIDADE DE SISTEMAS CONTABILÍSTICOS}

Qualquer um de nós se poderá questionar porque é que as normas contabilísticas diferem de país para país. Em última análise e de uma forma simplista, o objectivo da contabilidade, enquanto sistema que elabora informação económica e financeira sobre as empresas, não é o de quantificar e divulgar os activos, passivos, receitas e despesas de uma entidade económica? Não deveria haver apenas uma única forma de efectuar tal representação? A verdade é que a forma "correcta" depende, em grande medida, da perspectiva de cada um. A contabilidade não é matemática ou qualquer outra ciência exacta. Em nosso entender é uma disciplina que se insere no ramo das ciências sociais e que se vai ajustando ao tipo de informação que a sociedade deseja obter das empresas. Nesta perspectiva, as normas contabilísticas de determinado país podem ser influenciadas por uma multiplicidade de factores. Os procedimentos contabilísticos são uma resultante do interface com várias envolventes como sejam a cultura, os sistemas político, religioso e económico do país onde são postos em prática.

Muitos foram os estudos realizados ${ }^{6}$ que evidenciaram a existência de circunstâncias próprias, caracterizadoras do processo de elaboração da informação contabilística de cada país e que permitiram estabelecer determinadas correlações entre os diferentes sistemas contabilísticos. Estes sistemas evoluíram, de acordo com GONZALO e TÚA (1988: 49), por causas internas (por exemplo, à medida que se alteram os valores culturais ou sociais), externas (o paradigma pode ser a cada vez maior relevância e incidência das multinacionais) ou mistas (como o que sucedeu no âmbito da União Europeia, em que houve necessidade de alterar os normativos contabilísticos dos distintos países comunitários por forma a adaptá-los à legislação comunitária).

Nos últimos anos, tem-se observado um curioso processo de simplificação nas classificações dos diferentes sistemas contabilísticos. Desde os primeiros trabalhos de G. G. Mueller (1967), às complexas ordenações dos sistemas contabilísticos de K. Oldham (1975), que os representava graficamente de acordo com critérios macro/microeconómicos e uniforme/pragmático, até às classificações propostas pela American Accounting Association (1977) ou aos trabalhos mais recentes de Nobes e Parker (1991), com critérios de ordenação mais próximos da biologia do que da contabilidade (classe, subclasse, família, espécie e indivíduo), passámos às formas de classificar quase dicotómicas que, não obstante perderem em exactidão, ganham em realidade. 
Neste esforço de síntese, NOBES (1996b: 13) elaborou o seguinte quadro-resumo, no qual agrupa os países em dois blocos distintos: anglo-saxónico versus continental.

Quadro 1

AGRUPAMENTOS INTERNACIONAIS

\begin{tabular}{|c|c|}
\hline BLOCO ANGLO-SAXÓNICO & BLOCO CONTINENTAL \\
\hline \multicolumn{2}{|l|}{1 - Antecedentes } \\
\hline $\begin{array}{ll}\checkmark & \text { Direito inglês; } \\
\checkmark & \text { Profissão antiga, de grande } \\
& \text { dimensão e forte; } \\
\checkmark & \text { Grandes mercados de capitais. }\end{array}$ & $\begin{array}{ll}\checkmark & \text { Direito romano; } \\
\checkmark & \text { Profissão ainda recente, de pequena } \\
& \text { dimensão e fraca; } \\
\checkmark & \text { Pequenos mercados de capitais. }\end{array}$ \\
\hline \multicolumn{2}{|c|}{ 2-Características Contabilísticas Genéricas } \\
\hline $\begin{array}{ll}\checkmark & \text { Orientada para a imagem verdadeira } \\
& \text { e apropriada; } \\
\checkmark & \text { Orientada para o investidor; } \\
\checkmark & \text { Muita divulgação; } \\
\checkmark & \text { Separação entre as regras } \\
& \text { contabilísticas e as fiscais; } \\
\checkmark & \text { Predominam os standards } \\
& \text { profissionais e a substância sobre a } \\
& \text { forma. }\end{array}$ & $\begin{array}{ll}\checkmark & \text { Orientada para a forma legal; } \\
\checkmark & \text { Orientada para o credor; } \\
\checkmark & \text { Pouca divulgação; } \\
\checkmark & \text { A fiscalidade domina as regras } \\
& \text { contabilísticas; } \\
\checkmark & \text { Predominam as disposições } \\
& \text { governamentais e a forma sobre a } \\
\text { substância. }\end{array}$ \\
\hline \multicolumn{2}{|c|}{ 3-Características Contabilísticas Específicas } \\
\hline $\begin{array}{ll}\checkmark & \text { Método da percentagem de } \\
& \text { acabamento; } \\
\checkmark & \text { Cálculo das amortizações de acordo } \\
& \text { com períodos de vida útil; } \\
\checkmark & \text { Não existência de reservas legais; } \\
\checkmark & \text { Não existência de provisões para } \\
& \text { impostos; } \\
\checkmark & \text { Reconhecimento como custos das } \\
\text { despesas do primeiro } \\
\text { estabelecimento. }\end{array}$ & $\begin{array}{ll}\checkmark & \text { Método do contrato acabado; } \\
\checkmark & \text { Cálculo das amortizações de acordo } \\
& \text { com regras fiscais; } \\
\checkmark & \text { Existência de reservas legais; } \\
\checkmark & \text { Existência de provisões para } \\
& \text { impostos; } \\
\checkmark & \text { Capitalização das despesas do } \\
& \text { primeiro estabelecimento. }\end{array}$ \\
\hline \multicolumn{2}{|l|}{ 4-Alguns Exemplos de Países } \\
\hline $\begin{array}{ll}\checkmark & \text { Austrália; } \\
\checkmark & \text { Canadá; } \\
\checkmark & \text { Dinamarca; } \\
\checkmark & \text { Estados Unidos da América; } \\
\checkmark & \text { Holanda; } \\
\checkmark & \text { Nova Zelândia; } \\
\checkmark & \text { Reino Unido. }\end{array}$ & $\begin{array}{ll}\checkmark & \text { Alemanha; } \\
\checkmark & \text { Bélgica; } \\
\checkmark & \text { França; } \\
\checkmark & \text { Grécia; } \\
\checkmark & \text { Itália; } \\
\checkmark & \text { Japão; } \\
\checkmark & \text { Portugal. }\end{array}$ \\
\hline
\end{tabular}

Fonte: Adaptado de NOBES (1996b). 
Para NOBES (1996b), possivelmente, uma das principais causas das diferenças contabilísticas a nível internacional relaciona-se com a variação no método predominante de financiamento das empresas. Os Estados Unidos da América (EUA) e o Reino Unido (RU), expoentes máximos do modelo anglo-saxónico, têm uma longa história de obtenção de recursos financeiros via um conjunto alargado de investidores e financiadores exteriores à empresa. Nestes países, os grandes financiadores das empresas são os accionistas, pelo que toda a informação financeira está orientada para o investidor bolsista que, não tendo acesso à informação interna da empresa, pressionou no sentido da sua divulgação pública. Tal facto fez desenvolver as práticas contabilísticas nestes países, como sejam, a consolidação de contas, a demonstração dos fluxos de caixa, o relato financeiro intercalar, a informação financeira segmentada e os preços de transferência, entre outros.

Noutros países, como no caso da Alemanha, França, Itália e Japão, existe uma tradição de financiamento das empresas por parte dos bancos, do Estado ou de pequenos grupos financeiros familiares. Nestes países, os investidores privados assim como a necessidade de publicação e auditoria das contas, têm pouca importância. Uma vez que muitas empresas são dominadas por seguradoras, por bancos, pelo Estado ou por famílias de proprietários, estes não necessitam de uma informação financeira detalhada na medida em que, sendo detentores do capital da empresa, pertencem à sua administração; ou seja, são simultaneamente preparadores e utilizadores da informação financeira. Dada a importância dos capitais alheios e consequentemente dos credores existe, nestes países, uma tendência para um menor optimismo na utilização do princípio da prudência, aquando da medição e valorimetria de activos e passivos.

Uma outra causa responsável por muitos desequilíbrios a nível internacional é a influência da fiscalidade na contabilidade (NOBES, 1996b). Os sistemas clássicos, marcadamente europeus, têm da fiscalidade a noção de que o Estado é um sócio, um parceiro invisível e não um custo. Nos países de influência continental (França, Alemanha, Espanha e Portugal), a predominância dos impostos na contabilidade é marcante, uma vez que se entende que a informação financeira serve, em grande medida, para determinar o montante de imposto a pagar pela empresa. As regras fiscais sobrepõem-se às contabilísticas, obrigando as empresas a registar custos e proveitos de acordo com as primeiras, verificando-se, nalguns casos, uma subversão na aplicação dos princípios contabilísticos geralmente aceites (pcga's). 
Por seu lado, nos EUA e no RU o relato financeiro é concebido, primordialmente, no sentido de ser útil para os mercados de capitais e não para efeitos de determinação da matéria colectável das empresas. Como tal, verifica-se um alto grau de separação entre as normas contabilísticas e fiscais. Nestes países, onde predomina um sistema contabilístico de raíz anglo-saxónica, reconhece-se que o principal objectivo das demonstrações financeiras é o de fornecer uma imagem verdadeira e apropriada da posição financeira da empresa e dos resultados das operações por ela efectuadas e, nessa medida, os critérios fiscais não devem interferir na obtenção dessa mesma informação. Por conseguinte, nestes países o resultado fiscal acabará por usar, como ponto de partida, o resultado contabilístico, introduzindo-lhe as correcções extracontabilísticas tidas como necessárias, em face das exigências próprias do sistema tributário.

NOBES (1996b) refere ainda a relevância do sistema legal como factor determinante das diferenças contabilísticas, entre os dois agrupamentos de nações. De entre os países mais desenvolvidos do mundo existem dois sistemas legais distintos que, por sua vez, conduziram a dois padrões de desenvolvimento das práticas contabilísticas: o Codified Roman Law e o Common Law. A maior parte dos países da Europa Continental tem um sistema legal baseado no direito romano, de orientação legalista, cujas leis contêm um conjunto de obrigações que estabelecem normas mínimas que determinam o comportamento que se espera dos cidadãos. Em países como a França, Itália, Alemanha, Espanha e Portugal, as leis estão ligadas a ideias de justiça e de moralidade, tornando-se doutrina. As leis das sociedades e os códigos comerciais estabelecem regras detalhadas para a contabilidade $\mathrm{e}$ para o relato financeiro. Por exemplo, na Alemanha a contabilidade das sociedades é uma extensão da lei das sociedades. Em França, Espanha e Portugal a maior parte do detalhe da legislação contabilística apoia-se em planos de contas emanados de comissões especializadas e aprovados pelos governos.

Muitos outros países usam uma versão do sistema legal inglês (Common Law) que tem como objectivo primordial dar solução a casos específicos, em detrimento da formulação de regras gerais para o futuro. Neste sistema, o Estado tende a não emitir normas contabilísticas, deixando que a profissão as elabore através de organismos de regulamentação contabilística, constituídos por vários grupos de interesse que têm a capacidade para atrair pessoas cuja competência técnica é garante do desenvolvimento e implementação de sistemas de mensuração 
e divulgação capazes de responder aos anseios dos utentes das demonstrações financeiras. As normas contabilísticas por eles emanadas tendem a ser flexíveis e rapidamente adaptáveis à realidade envolvente.

Em síntese: podemos dizer que os utentes da informação financeira, em países como os EUA e o RU, esperam obter uma imagem verdadeira e apropriada dos resultados e da posição financeira da empresa, que os ajude na tomada de decisões económicas e financeiras. Pelo contrário, em muitos outros países, o objectivo é o de assegurar a existência de uma contabilidade prudente com vista à proteç̧ão dos credores e/ou propiciar uma contabilidade uniforme que sirva de base à função tributária.

Um sintoma de tudo isto está bem patente no tamanho, idade, força e competência da profissão contabilística, que difere de país para país (NOBES, 1996b). Quanto mais influente for a profissão, em termos de regulamentação, maior é o seu desenvolvimento. Nesta perspectiva, países em que os princípios contabilísticos, ao invés de geralmente aceites, são legalmente definidos, são países em que a profissão não é respeitada pelo poder, que a vê sem sentido e, acima de tudo, sem capacidade para pensar ou raciocinar.

Contudo, não é objectivo deste nosso trabalho analisar a problemática da diversidade dos sistemas contabilísticos, mas antes centrar a nossa atenção nas tendências actuais que nos conduzem a uma "Contabilidade" cada vez mais universalista e que se pode definir como um corpo de princípios contabilísticos geralmente aceites pela grande maioria dos países e que poderão ter o potencial para ofuscar os normativos nacionais (estamo-nos a referir às International Accounting Standards (IAS) do IASC).

\section{A EVOLUÇÃO DA GLOBALIZAÇÃO CONTABILÍSTICA}

A utilização do termo genérico "globalização" está relacionada com o facto de que o caminho metodológico seguido foi diferente, tendo-se optado em algumas situações pela via da harmonização e noutras pela da uniformização ou normalização.

A harmonização pode ser definida, de acordo com NOBES e ALEXANDER (1994), como o processo que visa incrementar a compatibilidade das práticas contabilísticas, mediante o estabelecimento de limites ao seu grau de variação. Talvez uma das experiências mais representativas deste processo tenha sido a vivida no seio dos países comunitários, onde a harmonização contabilística se apresenta como parte 
integrante da harmonização do direito das sociedades e, portanto, com fortes ligações à legislação promulgada pela União Europeia. Normalmente, a harmonização está relacionada com o cumprimento de requisitos de consenso e por isso é mais fácil de implementar, a curto prazo. Deste modo, não é de estranhar que, para que se atinja o consenso desejado, uma das suas consequências mais evidentes seja a inclusão de várias opções no tratamento de questões em que há incompatibilidade de posições (HULLE, 1997).

A normalização, pelo contrário, implica a imposição de normas mais rígidas e restritas (NOBES e ALEXANDER, 1994). Podemos apontar como exemplo ilustrativo desta experiência a actividade levada a cabo pelo IASC e que se tornou mais evidente desde a elaboração, em 1989, da Estrutura Conceptual para a Preparação e Apresentação das Demonstrações Financeiras. Aqui se encontram definidos os fundamentos para o desenvolvimento de novas normas e para a eventual revisão das já existentes, mediante a definição precisa dos elementos constantes das demonstrações financeiras e o estabelecimento de regras para o seu reconhecimento e mensuração.

Independentemente da metodologia que queira empregar-se, ambas visam o mesmo objectivo, ou seja, pretendem que a acontecimentos e transacções semelhantes seja dado o mesmo tratamento contabilístico e de relato financeiro, por parte das diferentes empresas sediadas em diferentes países. Da mesma forma, se deverá assegurar diferentes tratamentos contabilísticos para diversas transacções e eventos. Esta busca de uma normalização contabilística é tanto mais importante se se recordar que fazem parte dos objectivos essenciais da informação financeira a protecção dos interesses dos investidores e a comparabilidade da informação disponível. Esta comparabilidade - ao nível de empresas do mesmo grupo, sector ou indústria, operando em países diferentes e sujeitas a diferentes políticas e princípios contabilísticos adoptados pode ser posta em causa pela flexibilidade no tratamento contabilístico de alguns fenómenos patrimoniais, quer a nível de um país, quer a nível de um espaço mais amplo e integrado.

Nesta perspectiva, propomo-nos agora analisar, de forma breve, as diferentes estratégias seguidas no âmbito da União Europeia e as desenvolvidas pelo IASC, como a base sobre a qual se construirá, seguramente, a etapa final do processo de harrmonização contabilística. 


\subsection{Harmonização Contabilística na União Europeia}

Segundo NOBES (1996a), é possível caracterizar a estratégia desenvolvida pela União Europeia, por forma a alcançar uma desejável harmonização contabilística, num processo do tipo governamental, o qual envolve representantes dos diferentes Estados Membros que preparam projectos de lei baseados numa deficiente estrutura conceptual. Trata-se de um sistema contabilístico suportado pelo poder político e que funciona, pois está explicitamente dotado de autoridade normativa, forçando ao cumprimento das leis.

A produção de directivas, por parte da União Europeia, no âmbito da lei das sociedades comerciais, tem sido o instrumento de harmonização contabilística utilizado. De facto, a União Europeia tem produzido directivas que foram transpostas para o direito interno de cada Estado Membro e às quais estes têm de dar cumprimento. A $4^{\mathrm{a}}$ e a $7^{\mathrm{a}}$ directivas são as mais importantes em termos contabilísticos. A $4^{\mathrm{a}}$ directiva (78/660/CEE) trata da estrutura e apresentação das contas anuais, bem como do conteúdo do relatório de gestão e da publicidade dos documentos de prestação de contas e a $7^{\mathrm{a}}$ directiva (83/349/CEE) refere-se aos procedimentos de consolidação de contas.

No entanto, para se obter o necessário acordo político, as directivas pecam por omitirem determinados assuntos controversos ou por permitirem uma diversidade de tratamentos contabilísticos alternativos. Outras restrições à sua eficácia relacionam-se com o facto de uma vez aprovadas as directivas, o processo se tornar inflexível, pelo que muito dificilmente estas acompanham as alterações na envolvente económica e social.

Mas, não nos podemos esquecer, também, do enorme desafio com que se deparou a harmonização contabilística europeia, na tentativa de superar as concepções de dois sistemas contabilísticos radicalmente opostos, como são o chamado continental e anglo-saxónico, o que nos leva a reconhecer o enorme esforço integrador europeu, ao conseguir que países com tantas diferenças contabilísticas, como a Alemanha e o Reino Unido, tenham ratificado um texto tão complexo como o da $4^{\text {a }}$ directiva.

Por este motivo, não será de estranhar o facto de a norma comunitária estar impregnada de um excesso de opções e, mais ainda, estar nitidamente influenciada pelo Relatório Elmendorff de 1967 (e, consequentemente, pelo código das sociedades alemão), mas logo suavizada com a introdução da expressão britânica "true and fair view" "7 
(inexistente na legislação comercial alemã), característica do sistema anglo-saxónico.

Em 1990, num encontro realizado sobre o futuro da harmonização contabilística na União Europeia (HULLE, 1997), para além de ter ficado bem patente a divergência de objectivos dos vários países comunitários, quando se acordou a conveniência de manter o importante número de opções que admitem as directivas (em contraste com a estratégia que o IASC já estava a levar a cabo no sentido de reduzir a existência de tratamentos alternativos nas suas normas), a Comissão anunciou que não haveria mais grandes directivas comunitárias contabilísticas. Trata-se do reconhecimento da fraqueza do processo de harmonização europeu, admitindo-se que a solução deverá ter em conta o desenvolvimento conseguido a nível internacional.

Neste contexto, a Comissão adoptou, em Novembro de 1995, uma nova estratégia contabilística designada de "Harmonização Contabilística: uma nova estratégia na direcção da harmonização internacional" ${ }^{\text {, }}$, que consiste em compatibilizar, para as contas consolidadas, as normas comunitárias e as normas de cada país, em particular, com as normas internacionais de contabilidade. Ou seja, em tomar como base de referência as soluções do IASC, com vista a assegurar que, deste modo, as demonstrações financeiras emitidas por empresas da União Europeia sejam comparáveis e possam ser aceites, sem modificações, em outras áreas ou países.

O acordo celebrado entre o IASC e a International Organization of Securities Commissions (IOSCO) ${ }^{9}$ justifica o porquê da Comissão se ter associado aos esforços destas organizações internacionais, no que nos parece venha a ser a estratégia futura de harmonização europeia. Julgamos ser conveniente, nesta altura, analisar os êxitos obtidos pelo IASC no seu processo de normalização e a sua adequação aos objectivos previstos pelo legislador comunitário ${ }^{10}$.

\subsection{Normalização no Seio do IASC}

Diferentemente da metodologia seguida na União Europeia, o IASC procura alcançar o seu objectivo de homogeneização da informação financeira através da normalização das práticas contabilísticas. Não se pode afirmar se se trata ou não de uma decisão acertada, mas antes salientar que esta estratégia de normalização se apresenta como a mais racional ao não se referir, necessariamente, a um consenso, dada a falta de 
capacidade coercitiva do IASC para impor as suas normas. O que se tem verificado é que, à medida que os profissionais vão aceitando as normas, num processo cada vez mais generalizado dada a vocação internacional da contabilidade, podemos dizer que esta interiorização tem constituído a base para a internacionalização das mesmas.

As pressões exercidas pelas empresas multinacionais e pelas empresas de auditoria, no sentido de uma harmonização contabilística à escala internacional, conduziram à criação, em 1973, do IASC. Constituído por associações de profissionais de vários países, desenvolveu um modelo de harmonização que se caracterizava por:

- envolver a profissão e não os governos;

- estabelecer normas de aceitação voluntária e não leis;

- utilizar uma estrutura conceptual, onde predomina a substância sobre a forma e a divulgação da informação financeira ao invés de a ocultar;

- ter como objectivo o de proporcionar, aos mercados financeiros, informação verdadeira e apropriada, motivado pela preocupação fundamental de auxiliar investidores e financiadores na tomada das suas decisões económicas e financeiras.

Não obstante estas características marcadamente anglo-saxónicas, sempre fizeram parte do seu Conselho representantes de organizações profissionais do Japão, Alemanha e França. A sua influência foi-se espalhando, cada vez mais, pelos países do bloco continental, à medida que as grandes empresas necessitavam de obter maiores recursos financeiros, só possíveis recorrendo aos mercados internacionais.

De entre as características do processo harmonizador do IASC, merecem-nos especial destaque as seguintes:

- o carácter participativo na elaboração das normas, que se vai reforçando com o passar do tempo;

- o formato escolhido para as normas internacionais de contabilidade, o qual permite a justificação das alternativas contabilísticas escolhidas;

- a oportunidade dos temas seleccionados pelo IASC, encontrandose entre os mais controversos no âmbito da contabilidade;

- a evolução progressiva, das normas em vigor;

- a multiplicidade de aplicações que as normas conseguiram obter, podendo servir tanto de regras contabilísticas directamente aplicáveis a empresas multinacionais como de suporte ao desenvolvimento de uma normalização racional. 
Reconhecendo que existem em diferentes países formas diversas de tratar contabilisticamente uma mesma matéria e que muitas jurisdições nem sequer ainda abordaram muitas áreas contabilísticas, o IASC optou por uma estratégia multifacetada, desenhada para servir uma audiência tanto mais vasta quanto possível. Assim, EPSTEIN e MIRZA (1998) referem o conjunto de medidas utilizadas pelo IASC, por forma a dar continuidade aos seus objectivos:

1. persuadir os seus membros a convidar o IASC sempre que dois ou mais países, que não partilhem da mesma legislação, se proponham a discutir sobre princípios contabilísticos;

2. encorajar os países que não tenham normas contabilísticas próprias a adoptar as do IASC como normas nacionais do país;

3. convidar outros países que, apesar de terem normas próprias, carecem de regulamentação em certos assuntos particulares, a adoptar as soluções do IASC como a base para a emissão de normas nacionais nessa matéria em concreto; garantem, desta forma, um certo nível de qualidade e compatibilidade para aquela norma em particular, reduzindo, simultaneamente, tanto o tempo como os custos de desenvolvimento necessários à produção da mesma;

4. sugerir aos países que já têm normas de contabilidade a necessidade de as comparar com as normas internacionais com vista a eliminar qualquer diferença significativa;

5. esforçar-se por demonstrar àqueles países, que têm a estrutura das suas práticas contabilísticas definida na lei, os benefícios de uma harmonização com as normas internacionais de contabilidade.

$\mathrm{Na}$ tentativa de acomodar abordagens tão diversas, o IASC optou, inicialmente, por lidar com princípios gerais, evitando detalhes excessivos. Em consequência, o trabalho do IASC foi objecto de diferentes entendimentos, tendo sido nomeadamente considerado de vanguarda por países com escasso normativo contabilístico, enquanto que outros o rotularam de elementar, em particular países como o Reino Unido e os Estados Unidos da América, onde a contabilidade está mais avançada e onde as normas são numerosas, extensas e complexas.

Contudo, o seu propósito tem consistido em eliminar, com o decorrer do tempo, práticas contabilísticas consideradas pouco satisfatórias, reconhecendo tratar-se de um processo evolutivo, que não acontece de um dia para o outro, dada a natureza dos desafios com que se depara.

Recentemente, tem-se assistido a uma tendência que vai no sentido de acrescentar mais detalhe nos requisitos das normas, por forma a dar 
resposta às exigências colocadas pela IOSCO, que pretende um corpo de normas compreensível e de interpretação e aplicação consistente, que proporcionem a harmonização/normalização dos procedimentos e das sínteses contabilísticas.

Não obstante a tentativa de satisfazer os requisitos da IOSCO ter forçado o IASC a desviar-se, de certa forma, da sua prática histórica e filosofia de acção, conseguir que a IOSCO determine que as demonstrações financeiras preparadas de acordo com o novo conjunto de normas internacionais de contabilidade (core standards) sejam aceites em todas as bolsas de valores mundiais (excepto nas dos EUA) é, sem dúvida, um acontecimento de extrema importância para o IASC, pelo que não é de estranhar que tal mudança de rumo se tenha operado sem qualquer recriminação ou arrependimento.

\section{A RÁPIDA APROXIMAÇÃO À NORMALIZAÇÃO DO IASC}

Os compromissos celebrados pelo IASC com organizações de tanto prestígio como a IOSCO (que agrupa as entidades supervisoras das bolsas de valores de cerca de 100 países, entre as quais cabe destacar a norteamericana: Securities and Exchange Commission), bem como a recomendação da Federação das Bolsas Euro-asiáticas (com vinte membros pertencentes a dezoito países), juntamente com a efectuada pela The Arab Society of Certified Accountants, para que se adoptem as normas internacionais de contabilidade como corpo normativo das nações árabes, têm provocado um reconhecimento crescente das importantes contribuições do IASC no processo normalizador, subestimando o papel levado a cabo pela União Europeia (ÁLVAREZ, 1998).

E se já não bastassem estes desenvolvimentos à escala internacional, a própria Comissão da União Europeia abandonou o projecto de elaborar um corpo normativo próprio para trabalhar em conjunto com o IASC (HULLE, 1997). Esta política de aproximação ao normativo do IASC atraiu, não só os países comunitários como a França e a Alemanha, mas também algumas potências económicas como a China, Austrália e Japão e, inclusivamente, muitos países em vias de desenvolvimento. Estes encontram nas normas do IASC uma importante economia de custos de investigação (embora à custa de perder parte da sua soberania nacional ao adoptar um conjunto de normas "estranhas" para regular os interesses económicos nacionais) e uma forma de captar investidores estrangeiros ao facilitar-lhes um conjunto de regras mais transparentes. 


\subsection{Desenvolvimentos na União Europeia}

Durante muitos anos, a União Europeia viu no IASC um rival em termos de normalização contabilística. Como vimos anteriormente, as filosofias destes dois organismos são bastante diferentes. Em particular, a União Europeia sentiu que não podia apoiar as normas emitidas por um organismo do sector privado, sem qualquer autoridade legal explícita. No início de 1995, a Comissão Europeia ainda colocava as hipóteses de constituir um organismo normalizador europeu, sob o seu controlo, ou alargar o âmbito das directivas.

De facto, as directivas atingiram um certo grau de harmonização, em particular:

- redução da variedade de formatos das demonstrações financeiras, sem no entanto conseguir a sua eliminação para apenas um;

- aumento das divulgações e a exigência de auditorias às contas das empresas;

- a obrigatoriedade de elaborar demonstrações financeiras consolidadas em toda a União Europeia, situação rara, ou praticamente inexistente, em muitos países comunitários, no início da década de oitenta.

No entanto, o panorama actual caracteriza-se por uma União Europeia que, apesar dos seus esforços e avanços, não conseguiu harmonizar as práticas contabilísticas dos países comunitários. A sua norma contabilística de referência, a $4^{\text {a }}$ directiva, contém uma grande quantidade de opções que, por um lado, se torna necessário reduzir por forma a melhorar a comparabilidade, mas, por outro, parece improvável de ser conseguido pois dificilmente se chegaria a um consenso com vista à sua aceitação. E ainda que tal fosse possível, não nos esqueçamos que os prazos de negociação e transposição das normas são bastante alargados e os problemas actuais requerem soluções a curto prazo. O comunicado da Comissão, de Novembro de 1995, COM(95)508, vem reforçar esta ideia, advertindo que a actualização das directivas levaria ao reavivar de velhas polémicas e, por conseguinte, dever-se-á tentar desbloquear o processo de harmonização contabilística, o que poderá passar pela adopção do modelo do IASC.

$\mathrm{Na}$ Europa, as directivas comunitárias obrigam à elaboração e divulgação da informação financeira, mas apesar da consistência do aspecto exterior, permanecem diferenças que comprometem de forma substancial a transparência e comparabilidade da informação. A implementação de reformas tem, por isso, carácter de urgência, na medida 
em que, se tal não acontecer, as inconsistências continuarão e o relato financeiro europeu permanecerá fragmentado, impedindo, desta forma, o desenvolvimento de um eficiente e competitivo mercado de capitais europeu.

Paralelamente, a instituição da União Económica e Monetária (UEM) exige uma homogeneização das práticas contabilísticas entre os países que a constituem. Para que a União Europeia e, em particular, a UEM se possa afirmar como potência mundial, para além do euro, necessitará de regras contabilísticas à altura da moeda única. É impensável que para o euro existam doze contabilidades diferentes. Ao euro tem de corresponder uma expressão contabilística uniforme. Não será possível que cada país produza contas em euros, que em tudo pareçam iguais às dos outros países, mas que na prática sejam diferentes e até não comparáveis, porque as normas contabilísticas aplicadas foram diferentes.

O objectivo central vai, pois, no sentido de que as empresas possam apresentar-se livremente nos mercados de capitais europeus e mundiais, produzindo um único grupo de contas, preparadas em conformidade com um único conjunto de normas. Para que esta estratégia tenha sucesso é crucial que ela se encontre ancorada à melhor prática internacional.

Actualmente, no seio da UE, é permitido às grandes empresas (global players) utilizarem uma de duas estruturas de relato financeiro, apoiadas em normativos contabilísticos reconhecidos internacionalmente, designadamente os United States Generally Accepted Accounting Principles (US GAAP) ou as International Accounting Standards (IAS), para a elaboração das suas contas consolidadas, ao invés de darem cumprimento às normas nacionais. Ambos são sistemas de relato financeiro orientados para o investidor, proporcionando níveis equivalentes de salvaguarda dos seus interesses.

A escolha pelo melhor conjunto de normas contabilísticas e de relato financeiro poderia, muito bem, ser feita pelo próprio mercado. Contudo, e na opinião da Comissão Europeia, este processo iria prolongar, desnecessariamente, o período de competição entre as duas estruturas concorrentes, para além de que, enquanto durasse o processo de selecção, os custos não seriam reduzidos, nem a transparência melhorada [COM(2000)359: §15].

A Comissão, na sua estratégia contabilística de 1995, expressou a sua preferência pelas IAS, tendo, desde então, apoiado os esforços conjuntos do IASC e da IOSCO com vista à criação de um único conjunto de normas de relato financeiro a dar cumprimento por parte das empresas 
cotadas, ou que pretendam ser admitidas à cotação, em qualquer praça financeira do globo.

Um dos factores que mais contribuiu para esta tomada de posição, por parte da União Europeia, foi a consciencialização gradual de que, se o IASC não for bem sucedido nos seus planos de reconhecimento mundial, as grandes empresas europeias não teriam outra alternativa senão optar pelos US GAAP, sobre os quais a União Europeia tem bastante menos influência, ou até mesmo nenhuma, comparativamente com as normas do IASC. De facto, a única alternativa ao alcance das muito grandes empresas é a elaboração de Demonstrações Financeiras de acordo com os US GAAP, que são aceites quer no mercado americano, quer em grande número de bolsas de valores mundiais.

Agora que a finalização do corpo de normas se encontra concluída por parte do IASC e com o anúncio, em 17 de Maio de 2000, da conclusão do respectivo processo de avaliação pela IOSCO, a qual recomendou que os seus membros autorizem a utilização das IAS na preparação das demonstrações financeiras por parte das empresas multinacionais que pretendam ser admitidas à cotação e negociação nas bolsas de valores sobre sua jurisdição, a Comissão Europeia não perdeu tempo. Com efeito, anunciou, no seu comunicado de 13 de Junho de 2000 intitulado " $E U$ Financial Reporting Strategy: The Way Forward" [COM(2000)359], que a estratégia da UE para o futuro, em matéria de informações financeiras a prestar pelas empresas, passa pela adopção das IAS, deixando as empresas europeias cotadas de ser livres de escolher preparar as suas demonstrações financeiras consolidadas de acordo com os normativos contabilísticos nacionais, US GAAP ou IAS.

O recente comunicado é explícito ao anunciar que a Comissão Europeia, ainda antes do fim do ano 2000, irá apresentar, ao Conselho de Ministros e ao Parlamento Europeu, uma proposta legislativa, a qual exigirá que todas as empresas europeias cotadas em bolsas de valores (incluindo bancos e seguradoras) passem a preparar e apresentar as suas demonstrações financeiras consolidadas em obediência às IAS. Esta exigência deverá entrar em vigor, o mais tardar, a partir do ano 2005, deixando à consideração dos Estados Membros a opção de adopção das IAS a empresas não cotadas e às contas individuais.

$\mathrm{Na}$ opinião da Comissão, o sucesso desta estratégia é fundamental para o alcançar do importante objectivo de implementar, no espaço europeu, um eficiente e competitivo mercado de capitais, o qual necessita de um relato financeiro comparável e reconhecido internacionalmente, 
assente num normativo transparente, compreensível, correctamente auditado e de aplicação generalizada.

\subsection{A Crescente Importância do IASC}

A profissão contabilística desde há muito que reconheceu a necessidade de ter uma estrutura harmonizada à escala global. Há mais de vinte e sete anos, a profissão contabilística tomou a iniciativa de constituir o International Accounting Standards Committee (IASC) e o International Federation of Accountants (IFAC), com o intuito de produzir uma orientação em resposta às cada vez maiores exigências da comunidade empresarial. São estes dois organismos que estão incumbidos de desenvolver normas internacionais harmonizadas para a preparação e verificação da informação das organizações.

NOBES (1996a) refere que, nos seus primeiros anos de vida, o IASC era visto como uma arma inofensiva pelos principais países anglosaxónicos, embora muitos países da Europa Continental o encarassem como um "Cavalo de Tróia", que escondia o inimigo contabilístico anglosaxónico dentro de uma fachada internacional respeitável.

Contudo, toda esta situação começou a mudar à medida que o IASC atingia a sua maturidade, tendo assumido especial relevância a ocorrência de importantes desenvolvimentos no seu $21^{\circ}$ ano de vida (1993). Nesse ano registou-se uma importante série de eventos dos quais merecem particular destaque os seguintes (NOBES, 1996a):

- Hong Kong anunciou que iria no futuro basear as suas normas nas IAS, subentendendo-se que, possivelmente, a China também poderia fazer o mesmo;

- as normas revistas foram emitidas;

- a Comissão de Mercado de Valores Mobiliários norte-americana (Securities and Exchange Commission) aceitou que as empresas estrangeiras, cotadas nos seus mercados, apresentassem demonstrações de fluxos de caixa elaboradas com base na IAS 7 - Cash Flow Statements.

Depois destes acontecimentos, o IASC já fez consideráveis progressos na senda da sua aceitação mundial, sendo de destacar os seguintes (NOBES, 1996a):

- as normas contabilísticas, num número cada vez maior de países, baseiam-se fortemente, ou até mesmo na sua totalidade, nas IAS. É interessante verificar o caso de muitos países do leste europeu, 
que estão em vias de adoptar directamente o modelo do IASC sem desejarem implementar as directivas contabilísticas comunitárias;

- várias grandes empresas alemãs (e.g. Bayer, Deutsche Bank) começaram a utilizar as IAS na preparação das suas contas consolidadas, juntamente com, ou em alternativa, às normas alemãs;

- IOSCO e IASC anunciaram planos para a elaboração de um corpo de normas para todo o mundo;

- a União Europeia abandonou o seu propósito de elaborar um conjunto normativo próprio passando a alinhar na normalização contabilística do IASC;

- os organismos de normalização anglo-saxónicos passaram a coordenar as suas actividades na tentativa de evitar e eliminar diferenças existentes;

- o IASC tentou colocar-se à frente dos organismos de normalização nacionais na resolução de problemas contabilísticos novos, designadamente na área dos instrumentos financeiros, por forma a prevenir antecipadamente diferenças internacionais.

De acordo com EPSTEIN e MIRZA (1998), esta evolução experimentada pelo IASC é consequência de um desenvolvimento histórico que se pode identificar nas seguintes três etapas:

- a primeira relaciona-se com os primeiros anos, nos quais o IASC tentou chamar a atenção de todos com vista à sua aceitação generalizada, pelo que as suas normas eram breves e continham uma multiplicidade de opções. No entanto, e apesar do alcance limitado destas normas, esta estratégia serviu para estabelecer a legitimidade do IASC enquanto organismo de normalização contabilística transnacional, mas sem qualquer mecanismo que lhe permitisse ter autoridade normativa;

- a segunda etapa ficou marcada pelo designado "Projecto de Comparabilidade/Melhoramentos" (EPSTEIN e MIRZA, 1998: 11), que arrancou com a publicação do Exposure Draft (ED) n. ${ }^{\circ} 32$ (1989): Comparability of Financial Statements e com a criação de uma Estrutura Conceptual, em consonância com os trabalhos realizados nos EUA pelo Financial Accounting Standards Board (FASB), tendo ficado concluída, no ano de 1995, com a entrada em vigor de 10 normas revistas por forma a compatibilizar os seus conteúdos com os conceitos expressos na Estrutura Conceptual; 
- a terceira fase, que terminou em Março de 2000 com a aprovação do último projecto constante do acordo IOSCO/IASC (IAS $40-$ Investment Property), celebrado em Julho de 1995, caracterizou-se pela elaboração de um núcleo de normas internacionais de contabilidade com vista à sua adopção, pelas bolsas de valores mundiais, como os princípios contabilísticos geralmente aceites a usar na preparação e apresentação das demonstrações financeiras das empresas com valores mobiliários cotados naquelas praças, o que lhes conferirá o estatuto de quasi "Normas Mundiais de Contabilidade".

Apesar da IOSCO ter recomendado a todos os seus membros, em Maio de 2000, para permitirem aos emitentes multinacionais a utilização das normas do IASC e respectivas interpretações na preparação das suas demonstrações financeiras (o que é sem dúvida um marco importante para o incremento do relato financeiro à escala global), este acordo tem, ainda, um valor limitado. Isto deve-se ao facto de cada entidade supervisora manter o poder de decidir, individualmente, a extensão dos tratamentos adicionais a que ficam obrigadas as entidades que pretendam registar os seus valores mobiliários nas bolsas de valores sobre a sua jurisdição, com particular destaque para as praças financeiras dos EUA, Canadá e Japão, que ainda não autorizam a utilização das IAS.

O IASC deverá, pois, continuar a trabalhar arduamente na revisão dos normativos emitidos até ao momento e no desenvolvimento de novos projectos de acordo com as exigências da IOSCO, por forma a alcançar um elevado nível de concordância com esta organização que pretende ter um corpo de normas compreensível e de interpretação e aplicação consistente que proporcione a normalização dos procedimentos e das sínteses contabilísticas.

\section{CONCLUSÃO}

À escala global, os investidores estão a alargar os seus horizontes para além das fronteiras nacionais. Ao mesmo tempo, as empresas têm cada vez maiores exigências em termos de recursos financeiros que deverão ser satisfeitas à escala internacional. A interpenetração destas forças, associada às melhorias introduzidas nas tecnologias de comunicação, têm permitido integrar os mercados de capitais nacionais à escala mundial. Em consequência, muitas empresas estão interessadas no 
desenvolvimento de normas que sejam aceites em todos os grandes mercados de capitais mundiais.

A harmonização seria bastante fácil de ser conseguida se o seu objectivo fosse desenvolver normas que permitissem acomodar as preferências de todos os países - uma abordagem que tem sido caracterizada como a do mais baixo denominador comum. Uma outra perspectiva simplista seria a de negociar a harmonização como se de um leilão se tratasse e que teria como resultado um conjunto de regras com conceitos e objectivos pouco claros.

Qualquer corpo de normas de contabilidade, que pretenda uma aceitação global, deverá ser estruturado tendo em conta as necessidades dos investidores e dos mercados de capitais. Este não é, de facto, o caminho mais fácil, mas só assim se poderá assegurar que os mercados globais estão alicerçados em fundações firmes, factor crítico para o seu sucesso e sobrevivência a prazo. A harmonização das normas de contabilidade só será bem sucedida se essas normas proporcionarem informação credível assente num relato financeiro transparente.

Contudo, não se conseguirá satisfazer, por completo, as necessidades dos mercados de capitais apenas com a aprovação das normas pelo IASC e a sua recomendação pela IOSCO. Continuarão a existir diferenças substanciais entre os organismos de normalização nacionais e internacionais, conduzindo à consequente falta de comparabilidade entre as diferentes fronteiras políticas.

Torna-se, por isso, indispensável que o IASC trabalhe em parceria com os organismos nacionais de normalização contabilística, pois só assim é que se conseguirá melhorar a compreensão das diferenças actuais, aumentar o nível de coordenação dos projectos em agenda e, consequentemente, promover a eliminação das diferenças entre os normativos nacionais e internacionais. $\mathrm{E}$ isto porque, nos seus países, são eles que dispõem dos recursos, canais de comunicação e autoridade legal para implementarem as necessárias alterações às normas de contabilidade.

Assumindo que o IASC é bem sucedido nesta sua tarefa, a próxima questão consiste em saber o que irá acontecer quando um número significativo de entidades espalhadas por todos os cantos do globo preparar as suas demonstrações financeiras em conformidade com as IAS? Irão as normas ser interpretadas e aplicadas de forma consistente e como é que se assegurará o seu cumprimento?

É provável que num período inicial a consistência de interpretações das IAS seja bastante menor do que aquela que as entidades supervisoras considerariam desejável. Em alguns casos, esta situação poderá resultar 
de "interpretações criativas", por forma a tentar enquadrar uma prática nacional enraizada dentro do corpo de normas internacionais de contabilidade. Em outros casos, poderão existir diferenças genuínas de interpretação em resultado de diferentes abordagens filosóficas de natureza cultural. Também a existência de variações de terminologia poderá causar problemas de interpretação. Em nosso entender, uma divulgação compreensiva, de como as IAS deverão ser aplicadas a um conjunto de demonstrações financeiras, poderá contribuir para a tão necessária transparência pretendida pelos mercados de capitais.

Outro elemento-chave na promoção de uma consistente conformidade com as IAS será a educação, levada a cabo pelos organismos nacionais de contabilidade. As acções de formação deverão ter uma abordagem de curto e de longo prazo. No curto prazo, a atenção irá recair para a formação dos actuais profissionais. No longo prazo, o estudo das IAS deverá fazer parte dos currículos académicos da futura geração de profissionais.

Espera-se que o Comité Permanente de Interpretações do IASC, apesar de ser um organismo sem autoridade legal, desempenhe um importante papel na clarificação de situações ambíguas a que a aplicação das normas poderá conduzir, promovendo, desta forma, a sua correcta obediência.

Por tudo isto pode concluir-se que uma bem sucedida implementação das IAS irá requerer um significativo esforço de comunicação entre todas as partes envolvidas, incluindo os organismos de normalização nacionais, os preparadores e auditores das demonstrações financeiras, bem como das entidades supervisoras dos mercados de capitais, em todo o mundo.

\section{NOTAS}

${ }^{1}$ De que são exemplos a União Económica e Monetária (UEM), ao nível do espaço europeu, o North American Free Trade Agreement (NAFTA) e a Association of Southeast Asian Nations (ASEAN), entre outros.

${ }^{2} \mathrm{O}$ caso da famosa empresa alemã Mercedes Benz AG é sem dúvida um dos exemplos mais marcantes da diversidade de sistemas contabilísticos existentes. No ano de 1993, o resultado obtido pela empresa em conformidade com o normativo contabilístico alemão cifrou-se num lucro de cerca de 370 milhões de dólares americanos. $O$ interesse da empresa em passar a estar cotada nos mercados de capitais norte-americanos, obrigou à reconciliação das suas demonstrações financeiras com os US GAAP, tendo resultado na divulgação de um prejuízo brutal de um bilião de dólares (EPSTEIN e MIRZA, 1998: 19). 
${ }^{3}$ Os objectivos do IASC têm sido, precisamente, os de formular e difundir normas contabilísticas, promovendo a sua aceitação em todos os países do globo e trabalhar em todos eles por uma melhoria e harmonização das regras relacionadas com as demonstrações financeiras que as empresas emitem para utentes externos.

${ }^{4}$ A OCDE elaborou um conjunto de princípios directores para a empresa. No essencial, trata-se de recomendações com vista a melhor informar o público sobre a estrutura, actividades e políticas da empresa, em complemento às informações de divulgação obrigatória. A ONU foi mais longe, ao instituir um grupo intergovernamental de peritos em normas internacionais de contabilidade, com o objectivo de desenvolver e publicar normas para a apresentação da informação financeira pelas empresas multinacionais. Estes organismos limitam-se a fazer recomendações, na esperança que os países as adoptem.

${ }^{5}$ De alcance regional, o seu objectivo é o de, através das directivas, conseguir a harmonização de procedimentos e de documentos financeiros ao nível dos países comunitários. A $4^{\mathrm{a}}$ e a $7^{\mathrm{a}}$ directivas constituem o essencial do chamado "Direito Contabilístico Comunitário" aplicável às sociedades comerciais. Nelas encontramos as regras relativas à equivalência das condições jurídicas de elaboração da informação financeira a prestar ao público pelas sociedades obrigadas à sua aplicação, bem como as regras relativas à protecção dos interesses dos sócios, accionistas e terceiros.

${ }_{6}$ Muito embora alguns autores atribuam a Hatfield, em 1911, a primeira classificação dos sistemas contabilísticos, a sua simplicidade e reduzido impacto levaram a reconhecer os trabalhos de G.G. Mueller (1967) como os que definitivamente inspiraram toda esta linha de investigação.

${ }^{7}$ Os britânicos entendem que a contabilidade não pode, nem pretende alcançar a "verdade" e muito menos "uma só verdade". Do seu ponto de vista, e na nossa opinião bem, as demonstrações financeiras devem proporcionar uma "imagem verdadeira e apropriada" da posição financeira e do desempenho dos negócios.

8 "Rather than amend existing Directives, the proposal is to improve the present situation by associating the EU with the efforts undertaken by IASC and IOSCO towards a broader international harmonization of accounting standards" Excerto do comunicado da Comissão Europeia de Novembro de 1995, Accounting Harmonisation: A New Strategy vis-à-vis International Harmonisation, [COM(95)508]. (http://www.iasc.org.uk/frame/cen1_6_2.htm, 22 de Junho de 1999)

${ }_{9}$ Em Julho de 1995, a International Organization of Securities Commissions (IOSCO), organização sediada em Montreal, Canadá, que agrupa as várias Comissões de Mercado de Valores Mobiliários, tornou público um acordo com o IASC, no sentido de este proceder, até 1999 , a melhorias significativas às suas normas e criar outras para tratar novos assuntos pertinentes, findo o qual a IOSCO iria considerar a sua recomendação para serem aceites como corpo de normas a observar por todas as empresas estrangeiras já cotadas ou que pretendam ser admitidas à cotação em qualquer bolsa de valores mundial, o que veio a acontecer em Maio de 2000.

10 MARTÍNEZ (1996) entende que o objectivo do legislador comunitário, subjacente no texto definitivo da $4^{\text {a }}$ directiva, se pode resumir nos dois seguintes pontos:

- contribuir para a eliminação dos obstáculos à livre circulação de bens, serviços e capitais mediante a universalização da informação, e

- aceder ao financiamento internacional, por forma a alcançar uma distribuição mais eficiente dos recursos no mercado único. 


\section{REFERÊNCIAS BIBLIOGRÁFICAS}

ALEXANDER, D. e ARCHER, S. (1998), European Accounting Guide, $3^{\text {rd }}$ Edition, Harcount Brace \& Company.

ÁlVAREZ, F. J. Sosa (1998), “Aspectos actuales de la regulación contable a nível internacional”, Actas das VII Jornadas de Contabilidade e Auditoria, ISCAC, Coimbra, Tomo II, pp. 787-811.

AMERICAN ACCOUNTING ASSOCIATION (1977), "Report of the Committee on International Accounting Operations and Education", The Accounting Review, sup. pp. 65-132.

BELKAOUI, A. R. (1992), Accounting Theory, $3^{\text {rd }}$ Edition, The Dryden Press, Londres.

BLAKE, John e AMAT, Oriol (1993), European Accounting, Pitman Publishing, Londres.

CHOI, Frederick D. S. (1997), International Accounting and Finance Handbook, $2^{\text {nd }}$ Edition, John Wiley \& Sons, Inc., New York.

CHOI, Frederick D. S. e MUELLER, G. G. (1994), International Accounting, Prentice Hall, New Jersey.

COMMISSION OF THE EUROPEAN COMMUNITIES, (Ed.) (2000), EU Financial Reporting Strategy: the way forward, $\operatorname{COM}(2000) 359$ final, Communication from the Commission to the Council and the European Parliament, Brussels.

COSTA, Carlos B. da e ALVES, Gabriel C. (1999), Contabilidade Financeira, Vislis Editores, Lisboa.

EPSTEIN, Barry J. e MIRZA, Abbas Ali (1998), Interpretation and Application of International Accounting Standards (IAS) 98, John Wiley \& Sons, Inc., New York.

FERREIRA, R. Fernandes (1984), Normalização Contabilística, Livraria Arnado, Coimbra.

GONZALO, J. A. e TÚA, J. (1988), Introducción a la Contabilidad Internacional, IPC, Madrid.

HULLE, K. Van (1997), "La Armonización Contable Europea: Una nueva estrategia de cara a la armonización internacional", in AA.VV., Estudios de Contabilidad y Auditoría, ICAC, Madrid, pp. 87-106.

INTERNATIONAL ACCOUNTING STANDARDS COMMITTEE, (Ed.) (1983), Preface to Statements of International Accounting Standards, Londres. 
INTERNATIONAL ACCOUNTING STANDARDS COMMITTEE, (Ed.) (1989), Framework for the Preparation and Presentation of Financial Statements, Londres.

INTERNATIONAL ORGANIZATION OF SECURITIES COMMISSIONS, (Ed.), (2000), IASC Standards, Report of the Technical Committee of the IOSCO, Maio, s.1..

IUDÍCIBUS, S. (1989), Teoria da Contabilidade, $2^{\mathrm{a}}$ Edição, $2^{\mathrm{a}}$ tiragem, Atlas, São Paulo.

MARTÍNEZ, J. (1996), Contabilidad comparada en la Unión Europea, ICAC, Madrid.

MUELLER, G. G. (1967), International Accounting, McMillan, New York.

NOBES, C. W. (1994), A Study of the International Accounting Standards Committee, Albert Robins \& Co., Londres.

NOBES, Christopher (1996a), International Accounting Standards: Strategy, Analysis and Practice, FT Financial Publishing, Pearson Professional Limited, Londres.

NOBES, Christopher (1996b), International Guide to Interpreting Company Accounts 1996-97, FT Financial Publishing, Pearson Professional Limited, Londres.

NOBES, Christopher e ALEXANDER, David (1994), A European Introduction to Financial Accounting, Prentice Hall (UK) International, Hertfordshire.

NOBES, Christopher e PARKER, R. (1998), Comparative International Accounting, $5^{\text {th }}$ Edition, Prentice Hall Europe.

OLDHAM, K. (1975), Accounting Systems and Practice in Europe, Gower Press, Essex.

RADEBAUGH, Lee H. e GRAY, Sidney J. (1997), International Accounting and Multinational Enterprises, $4^{\text {th }}$ Edition, John Wiley \& Sons, Inc., New York. 